\title{
Lithium-magnesium Alloy as an Anode for Lithium-Sulfur Based Batteries
}

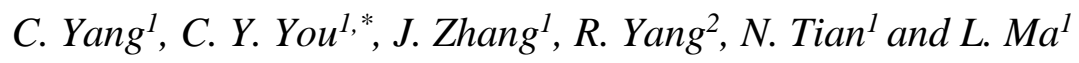 \\ ${ }^{1}$ School of Materials Science \& Engineering, Xi'an University of Technology, Xi'an 710048, P. R. \\ China \\ ${ }^{2}$ School of Sciences, Xi' an University of Technology, Xi'an 710048, P. R. China \\ *E-mail: caiyinyou@ Xaut.edu.cn
}

doi: $10.20964 / 2019.09 .25$

Received: 7 February 2019/ Accepted: 28 March 2019 / Published: 31 July 2019

\begin{abstract}
Lithium-sulphur (Li-S)-based batteries have received much attention due to their overwhelming theoretical energy density $\left(2500 \mathrm{Wh} \cdot \mathrm{kg}^{-1}\right)$. The modification of Li-based anodes is a critical issue relevant to the practical usage of $\mathrm{Li}-\mathrm{S}$ based batteries, considering the increasing cost of $\mathrm{Li}$ metal and the dendritical tendency of anodes. In this study, we demonstrated that a lithium-magnesium ( $\mathrm{Li}-\mathrm{Mg})$ alloy can also act as the anode of Li-S based batteries and perform comparably to Li. The electrochemical behavior of the Li-Mg alloy could be further improved by the surface nitridation and coating with a layer of molybdenum disulfide. There was no clear dendrite on the surface of the electrode. When the surface was nitrided, the stability of the battery was improved, and when the surface of the Li-Mg anode was coated with molybdenum disulfide by magnetron sputtering, the cycling performance of the electrode was improved, with an increased specific discharge capacity. Thus, this work suggests that the Li-Mg alloy could be a suitable material for replacing lithium as the anode material of Li-S based batteries.
\end{abstract}

Keywords: Lithium-Magnesium Alloy Electrodes, Surface Modification, Li-S Battery

\section{$\underline{\text { FULL TEXT }}$}

(C) 2019 The Authors. Published by ESG (www.electrochemsci.org). This article is an open access article distributed under the terms and conditions of the Creative Commons Attribution license (http://creativecommons.org/licenses/by/4.0/). 